\title{
Diagnostic sensitivity of extended renal and hematologic criteria to define hemolytic uremic syndrome
}

\author{
Alejandro Balestracci, M.D. ${ }^{a}$, Luciana Meni Battaglia, M.D. ${ }^{a}$, Ismael Toledo, M.D. ${ }^{a}$, \\ Sandra M. Martin, M.D. ${ }^{a}$, Iris Puyol, M.D. ${ }^{a}$, Laura Beaudoin, M.D. ${ }^{a}$ and \\ Natalia L. Robledo, M.D. ${ }^{a}$
}

\begin{abstract}
Introduction. The usual definition of Shiga toxin-producing Escherichia coli hemolytic uremic syndrome (STEC-HUS) is based on the presence of anemia, thrombocytopenia, and elevated serum creatinine levels, with or without proteinuria and/or hematuria. The strict definition only considers elevated serum creatinine levels as a renal criterion. The extended definition maintains flexible renal criteria, although it replaces anemia with hemolysis and considers a sharp drop in platelet count as an indicator of platelet consumption. The objective of this study was to estimate and compare the diagnostic sensitivity of these definitions in patients with STEC-HUS as hospital discharge diagnosis.
\end{abstract}

Population and methods. Retrospective review of medical records of HUS patients. Sensitivity and positive predictive value, with their corresponding $95 \%$ confidence intervals (CIs), were estimated for the 3 definitions based on a discharge diagnosis of STEC-HUS (reference diagnosis). The McNemar test was used.

Results. Out of 208 patients, 107 (51.4\%), $133(63.9 \%)$, and $199(95.6 \%)$ were identified with the strict, usual, and extended definition, respectively. Sensitivity was lower for the strict definition (51.4\%; $95 \%$ CI: 44.8-58.3), intermediate for the usual definition $(63.9 \% ; 95 \%$ CI: 56.9-70.4), and higher for the extended one (95.6\%; $95 \%$ CI: 91.6-97.8); $(p<0.001)$.

a. Nephrology Unit, Hospital General de Niños "Dr. Pedro de Elizalde", Autonomous City of Buenos Aires, Argentina.

E-mail address: Alejandro Balestracci, M.D.:

abalestracci@yahoo.

com.ar

Funding:

None.

Conflict of interest:

None.

Received: 10-18-2020

Accepted: 1-12-2021

\section{INTRODUCTION}

Shiga toxin-producing Escherichia coli hemolytic uremic syndrome (STEC-HUS) develops following a diarrhea episode, usually bloody, and is characterized by the presence of microangiopathic hemolytic anemia, thrombocytopenia, and acute kidney injury. ${ }^{1,2}$ It predominantly affects children younger than 5 years; renal involvement is present in all patients, and extrarenal manifestations may also be observed. ${ }^{1}$ Mortality in the acute stage is $3 \%$, mainly due to neurological involvement, and one third of patients have long-term sequelae, especially in the kidneys. ${ }^{3,4}$ In Argentina, HUS is one of the leading causes of acute kidney injury and kidney transplant in pediatrics, and a critical problem for public health with a high social, health care, and financial impact. ${ }^{3,5}$ According to official records, it is an endemic disease with the highest incidence worldwide. The average number of annual cases between 2014 and 2018 was 337 , and the incidence in 2019 was 6.23 cases / 100000 children younger than 5 years. ${ }^{6}$

The optimal case definition should maximize the inclusion of patients with STEC-HUS and minimize that of patients without this condition; however, considering its elevated incidence in Argentina, the lack of a specific treatment, and a high morbidity, a very sensitive definition would allow to optimize an early clinical management and make interventions to reduce bacterial dissemination. ${ }^{7}$ Several definitions have been accepted, ${ }^{7-12}$ with some differences in criteria, but it has not 
been determined how they affect diagnostic capability at a local level. The objective of this study was to estimate and compare the diagnostic sensitivity of the 3 most commonly used definitions in patients with STEC-HUS as diagnosis at the time of hospital discharge.

\section{POPULATION AND METHODS}

This was a retrospective, observational, analytical, and cross-sectional study. The study population included the medical records of patients consecutively admitted to a children's hospital between January $1^{\text {st }}, 2000$ and December $31^{\text {st }}, 2019$ that met the following criteria: diagnosis of HUS at hospital discharge and age younger than 18 years. The exclusion criteria were medical records with incomplete data and confirmed or suspected atypical HUS associated with systemic conditions and/or drugs.

STEC-HUS case definitions encompass 3 domains: renal, anemia, and thrombocytopenia. ${ }^{7-12}$ In this study, diagnosis at hospital discharge is the reference standard, and definitions to be assessed were as follows: a) usual definition, which was the most common one, ${ }^{8,9}$ b) strict definition, which includes more rigid criteria, $7,10,11$ and c) extended definition, based on more flexible criteria $^{12}$ (Table 1).

Studied outcome measures included the duration of the prodromal phase, the presence of watery or bloody diarrhea, age, and sex. The following laboratory parameters were recorded when the HUS diagnosis was noted in the medical record: hematocrit, platelet count, presence of schistocytes, lactate dehydrogenase (LDH) and creatinine levels, hematuria and/or proteinuria. Among patients without urine analysis, the presence of anuria was recorded; and, among those with normal hematocrit, creatinine and/ or platelet levels at the time of diagnosis, the number of days until a hematocrit reduction below $30 \%$, a creatinine increase above the limit, and a platelet reduction below $150000 / \mathrm{mm}^{3}$ was recorded. Microorganism isolation was also recorded. The study was approved by the local Ethics Committee.

\section{Definitions}

The diagnosis of STEC infection was confirmed by at least one of the following methods: Shiga toxin 1 and 2 gene detection by polymerase chain reaction (PCR), STEC isolation in stool culture, and free Shiga toxin detection in stools and/or anti-lipopolysaccharide antibody detection. ${ }^{2}$ In patients with negative results and in the absence of suspected or confirmed atypical HUS, a STEC infection was assumed. The prodromal phase was defined as the period between the first day of diarrhea and HUS diagnosis. ${ }^{13}$

Mechanical anemia was demonstrated by the presence of schistocytes in peripheral blood smear and/or increased serum LDH levels (younger than 1 year old: $>580 \mathrm{IU} / \mathrm{L}, 1-9$ years old: > $500 \mathrm{IU} / \mathrm{L}, 10-19$ years old: > $330 \mathrm{IU} / \mathrm{L}$ ) or both. ${ }^{14}$ The upper limit of creatinine (as per the Jaffé method) was established at $0.4 \mathrm{mg} / \mathrm{dL}$ for infants younger than 1 year and $0.7 \mathrm{mg} / \mathrm{dL}$ for children aged 1-12. ${ }^{14}$ Hematuria was defined as more than 5 red blood cells per field in urine, and proteinuria, as a positive strip test (+ or more)..$^{15,16}$ Assessed extrarenal complications included severe intestinal involvement, central nervous system involvement, multiple organ failure, heart damage, pancreatic injury, eye alterations and/ or death.

\section{Statistical analysis}

Continuous outcome measures lacked a normal distribution (Shapiro-Wilk test) and

TABLE 1. Diagnostic criteria of the three alternative hemolytic uremic syndrome definitions

\begin{tabular}{|c|c|c|c|}
\hline Definition & Criterion for anemia & Criterion for renal involvement & Criterion for thrombocytopenia \\
\hline Strict ${ }^{7,10,11}$ & $\begin{array}{c}\text { Hematocrit }<30 \% \text { with schistocytes } \\
\text { and / or elevated LDH level }\end{array}$ & $\begin{array}{l}\text { Serum creatinine level } \\
>\text { normal limit for age }\end{array}$ & $<150000 / \mathrm{mm}^{3}$ \\
\hline Usual $^{8,9}$ & $\begin{array}{c}\text { Hematocrit }<30 \% \text { with schistocytes } \\
\text { and / or elevated LDH level }\end{array}$ & $\begin{array}{l}\text { Serum creatinine level } \\
>\text { normal limit for age and / or } \\
\text { hematuria and / or proteinuria }\end{array}$ & $<150000 / \mathrm{mm}^{3}$ \\
\hline Extended $^{12}$ & $\begin{array}{l}\text { Mechanical hemolysis } \\
\text { (schistocytes and/or } \\
\text { elevated LDH level) }\end{array}$ & $\begin{array}{l}\text { Serum creatinine level } \\
>\text { normal limit for age and/or } \\
\text { hematuria and/or proteinuria }\end{array}$ & $\begin{array}{c}<150000 / \mathrm{mm}^{3} \\
\text { or sharp drop }>50 \%\end{array}$ \\
\hline
\end{tabular}

LDH: lactate dehydrogenase. 
were described as median (range). Categorical outcome measures were expressed as frequency of presentation and/or percentage, and compared using the $\chi^{2}$ test. The diagnostic sensitivity and positive predictive value with the $95 \%$ confidence interval (CI) of STEC-HUS definitions included here (strict, usual, and extended) ${ }^{7-12}$ were estimated based on the STEC-HUS diagnosis at hospital discharge (reference diagnosis). Since the study population was made up of patients with confirmed diagnosis, the specificity and negative predictive value of the different definitions were not estimated. The extended McNemar test as per Hawass was used to compare sensitivities. ${ }^{17}$ Since

TABLE 2. Characteristics of patients with hemolytic uremic syndrome included in this study

\begin{tabular}{lc}
\hline Characteristic & $\begin{array}{c}\text { N (\%) } \\
\text { Median (range) }\end{array}$ \\
\hline Number of patients & $208(100)$ \\
Sex (female/male) & $100(48) / 108(52)$ \\
Age (years) & $2.08(0.5-11.9)$ \\
Duration of prodromal phase (days) & $5(1-21)$ \\
Bloody diarrhea & $173(83)$ \\
Evidence of STEC infection & $109(52.4)$ \\
Need of dialysis & $102(49)$ \\
Extrarenal complications & $48(23)$ \\
Death & $5(2.4)$ \\
\hline
\end{tabular}

Data expressed as frequency of presentation (percentage) or median (range), as applicable.

STEC: Shiga toxin-producing Escherichia coli. the study period was 20 years, the sample was divided arbitrarily into 2 sub-periods (before and after 2010) to investigate if there were changes in the diagnostic sensitivity of the different definitions over time. The Statistix ${ }^{\circledR} 7.0$ software was used, and the $p$ value was established at $<0.05$.

\section{RESULTS}

During the study period, 210 patients were discharged from Hospital General de Niños "Dr. Pedro de Elizalde" with HUS diagnosis; all their medical records included sufficient data. Two patients were excluded from the study due to atypical HUS. The demographic and clinical characteristics of patients are summarized in Table 2.

Out of 208 studied patients, $107(51.4 \%), 133$ $(63.9 \%)$, and $199(95.6 \%)$ were identified with the strict, usual, and extended definition, respectively. A total of 107 patients met the 3 definitions, determined by the scope of the strict definition, whereas only 9 did not meet any definition, which corresponded to those who did not meet the extended definition criteria (Figure 1). The absence of anemia (hematocrit $<30 \%$ ) was the most common unmet criterion, which had an impact on both the strict and the usual definitions, since both include it (Table 3). Sixty-three patients $(30.2 \%)$ did not have anemia, but all of them presented findings compatible with mechanical hemolysis (schistocytes and/or elevated LDH

FIGURE 1. Number of patients identified with each hemolytic uremic syndrome definition, with all of them, and with none of them

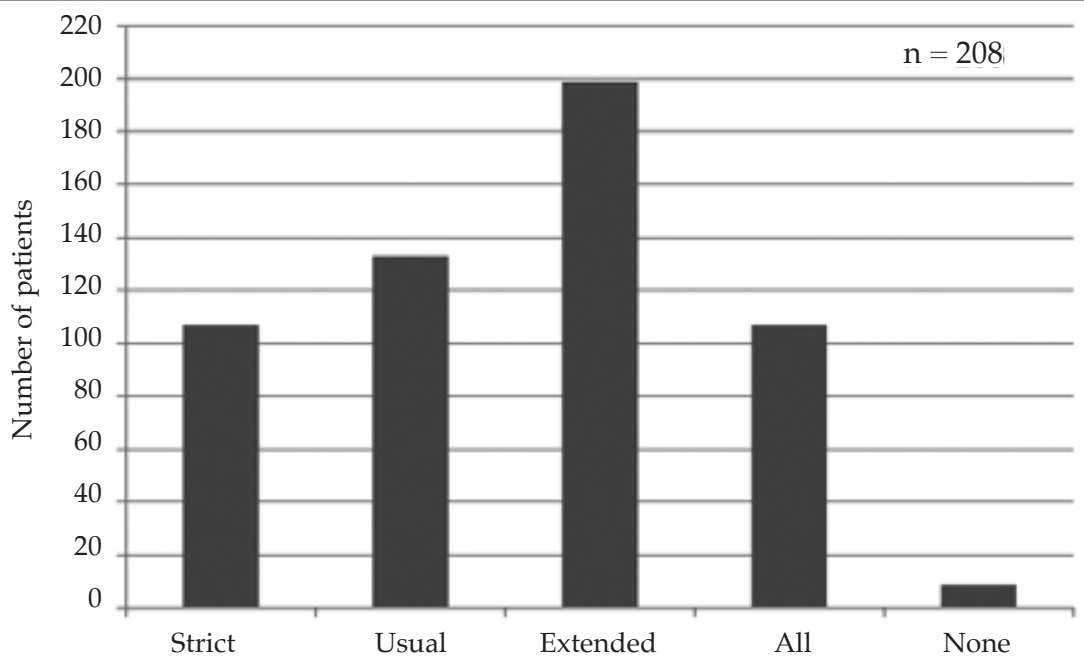


levels). Of them, 59 developed anemia after 2 days (range: $1-5$ ), whereas the other 4 did not develop anemia throughout the disease course. The absence of anemia upon admission was more common among patients with extrarenal

Table 3. Criteria that were not met as per the studied hemolytic uremic syndrome definitions

\begin{tabular}{lc}
\hline Unmet criterion & $\begin{array}{c}\text { Number of patients } \\
\mathbf{n}=\mathbf{2 0 8}\end{array}$ \\
\hline $\begin{array}{l}\text { Strict definition } \\
\text { Anemia }\end{array}$ & 49 \\
Anemia + high creatinine & 14 \\
High creatinine & 26 \\
Thrombocytopenia + normal creatinine & 4 \\
Thrombocytopenia & 8 \\
Total number of patients who do not & \\
meet the definition & 101 \\
Usual definition & \\
Anemia & 63 \\
Renal involvement (high creatinine & \\
and / or hematuria and / or proteinuria) & 0 \\
Thrombocytopenia & 12 \\
Total number of patients who & \\
do not meet the definition & 75 \\
Extended definition & \\
Mechanical hemolysis & \\
Renal involvement (high creatinine & \\
and / or hematuria and / or proteinuria) & \\
Platelet consumption & 0 \\
Total number of patients who & 9 \\
do not meet the definition & \\
\hline & \\
\hline
\end{tabular}

complications and / or death $(23 / 48$ versus $40 / 160 ; p=0.002$ ). An elevated creatinine level is a criterion only in the strict definition and failed to make an adequate classification of 40 patients $(19.2 \%)$; however, they all had kidney injury as expressed by hematuria and / or proteinuria. Fourteen of these patients exceeded the threshold value between 1 and 3 days after diagnosis; the remaining 26 patients maintained normal values until resolution of the acute condition. Unlike what was observed with the absence of anemia, this criterion was not associated with the presence of extrarenal complications and/or death $(6 / 48$ versus $34 / 160 ; p=0.17)$. In relation to the findings in urine samples, 17 patients developed isolated hematuria and 106, hematuria associated with proteinuria; there were no urine results for the remaining cases due to the presence of anuria. Lastly, 12 patients did not develop thrombocytopenia; but 3 patients, although they had values $>150000 / \mathrm{mm}^{3}$, showed a reduction of $>50 \%$ compared to the lab results from the previous day. A fourth patient had a drop in platelet count, although this was 3 days after hospitalization, so it was not considered a sharp drop. As a result, only 9 patients were not covered by the extended definition (all with values $>150000 / \mathrm{mm}^{3}$ of platelets without a sharp drop in platelet levels).

The diagnostic sensitivity was lower for the strict definition, intermediate for the usual definition, and much higher for the extended definition, with significant differences among

TABLE 4. Diagnostic sensitivity of the different studied hemolytic uremic syndrome definitions

\begin{tabular}{|c|c|c|c|}
\hline \multirow[t]{2}{*}{ Definition } & \multicolumn{3}{|c|}{ Correctly identified patients, diagnostic sensitivity, and positive predictive value } \\
\hline & $\begin{array}{c}2000-2019 \text { period } \\
\mathrm{n}=208\end{array}$ & $\begin{array}{c}2000-2009 \text { period } \\
n=122\end{array}$ & $\begin{array}{c}\text { 2010-2019 period } \\
n=86\end{array}$ \\
\hline Strict & $\begin{array}{c}\text { n: } 107(51.4 \%) \\
\text { S: } 51.4 \% \text { (95\% CI: 44.4-58.3) } \\
\text { PPV: } 100 \% \text { (95\% CI: 95.6-100) }\end{array}$ & $\begin{array}{c}\text { n: } 62 \text { (50.8) } \\
\text { S: } 50.8 \% \text { (95\% CI: 41.6-59.9) } \\
\text { PPV: } 100 \% \text { (95\% CI: 92.7-100) }\end{array}$ & $\begin{array}{c}\mathrm{n}: 45 \text { (52.3) } \\
\text { S: } 52.3 \% \text { (95 \% CI: 41.3-63.1) } \\
\text { PPV: } 100 \% \text { (95 \% CI: 90.2-100) }\end{array}$ \\
\hline Usual & $\begin{array}{c}\mathrm{n}: 133(63.9) \\
\text { S: } 63.9 \% \text { (95 \% CI: 56.9-70.4) } \\
\text { PPV: } 100 \% \text { (95\% CI: 96.5-100) }\end{array}$ & $\begin{array}{c}\text { n: } 78 \text { (63.9) } \\
\text { S: } 63.9 \% \text { (95\% CI: 54.7-72.3) } \\
\text { PPV: } 100 \% \text { (95\% CI: 94.1-100) }\end{array}$ & $\begin{array}{c}\text { n: } 55 \text { (64) } \\
\text { S: } 63.9 \% \text { (95\% CI: 52.8-73.8) } \\
\text { PPV: } 100 \% \text { (95\% CI: 91.8-100) }\end{array}$ \\
\hline Extended & $\begin{array}{c}\mathrm{n}: 199 \text { (95.6) } \\
\text { S: } 95.6 \% \text { (95 \% CI: 91.6-97.8) } \\
\text { PPV: } 100 \% \text { (95\% CI: 97.6-100) }\end{array}$ & $\begin{array}{c}\text { n: } 117 \text { (95.9) } \\
\text { S: } 95.9 \% \text { (95 \% CI: 90.2-98.4) } \\
\text { PPV: } 100 \% \text { (95\% CI: 96-100) }\end{array}$ & $\begin{array}{c}\text { n: } 82 \text { (95.3) } \\
\text { S: } 95.3 \% \text { (95 \% CI: 87.8-98.5) } \\
\text { PPV: } 100 \% \text { (95 \% CI: 94.4-100) }\end{array}$ \\
\hline
\end{tabular}

$\mathrm{N}$ : number of patients; S: sensitivity; PPV: positive predictive value; $\mathrm{CI}$ : confidence interval.

2000-2019 period: strict versus usual definition $(p<0.001)$; usual versus extended definition $(p<0.001)$.

2000-2009 period: strict versus usual definition $(p<0.001)$; usual versus extended definition $(p<0.001)$.

2010-2019 period: strict versus usual definition $(p=0.004)$; usual versus extended definition $(p<0.001)$.

2000-2009 period versus 2010-2019 period: strict $(p=0.83)$; usual $(p=0.99)$; extended $(p=1.00)$. 
them. On the other side, by dividing the analyzed period in two, it was observed that the sensitivity of the 3 definitions was similar (Table 4).

\section{DISCUSSION}

A potential barrier in the adequate management of STEC-HUS is the uncertainty resulting from the different commonly accepted case definitions. This is relevant because many patients seek care several times before obtaining a diagnosis, which is relatively simple because it is based on usually available laboratory tests. ${ }^{18}$ This study found a great difference in terms of sensitivity, which ranged from $51.4 \%$ for the strict definition to $95.6 \%$ for the more flexible definition. Since only patients with an established diagnosis of STEC-HUS were included, specificity was not estimated; however, given the high prevalence of this disease in Argentina, using a highly sensitive definition seems reasonable. From a clinical perspective, it is worth noting that diagnosis should be established as soon as possible so that the patient is admitted to the hospital for the timely implementation of the necessary support measures. ${ }^{7,19}$ Both the strict and the usual definitions require the presence of anemia; ${ }^{7-11}$ the absence of this condition was the most common cause of a wrong diagnosis across the series. A high hematocrit level indicates dehydration secondary to gastrointestinal losses, which has been observed in more than one third of patients at the time of admission. ${ }^{20}$ It is remarkable that hemoconcentration is associated to a poor prognosis, ${ }^{3,21-23}$ as confirmed by our series: its finding is significantly associated with the presence of extrarenal complications and/ or death. Therefore, since more severe patients do not usually have anemia at onset, ${ }^{3,21-23}$ these definitions may delay disease recognition, therefore missing the best chance for treatment (e.g., a rapid blood volume correction, which has demonstrated to be effective in reducing dialysis requirement and mortality) and/or transfer to a tertiary care facility..$^{24,25}$ Replacing anemia as an indispensable requirement with provable mechanical hemolysis based on the presence of schistocytes and/or increased LDH levels may facilitate an early STEC-HUS diagnosis. ${ }^{12}$ Haptoglobin consumption may also be used to this end, ${ }^{12}$ however, this study did not assess this parameter because it is not systematically performed in our hospital.

The strict definition is even less sensitive than the usual definition because, in addition to the hurdle of anemia, it requires an increased creatinine level as renal criterion. ${ }^{7,10,11}$ It is worth noting that documenting certain degree of kidney injury in mild or very early diagnosed cases may be difficult because creatinine levels may be within the normal range in spite of an increase of more than $50 \%$ from baseline, which is usually unknown. ${ }^{26}$ In addition, many children have hypoalbuminemia secondary to a low protein intake in the prior days; such hypercatabolism may also be accompanied by deceitfully low creatinine levels. ${ }^{27,28}$ Based on the cases presented by the authors, almost $20 \%$ of patients had normal creatinine levels at the time of admission, which would have prevented an adequate classification. Unlike what was observed with anemia, which developed in 59 cases during the course of disease, 26 maintained normal creatinine levels until discharge. However, including urinary findings (hematuria and/ or proteinuria) in the renal domain, as is the case with the usual definition, ${ }^{8,9}$ allowed to identify 26 additional patients, which significantly increased diagnostic sensitivity. Similarly, the extended definition also includes urinary findings with the subsequent improvement in sensitivity. ${ }^{12}$ Since urine may be contaminated in patients with diarrhea and hemoglobinuria detected by test strip may account for filtered free intravascular hemoglobin or myoglobinuria, some authors observed that the renal criterion based on creatinine levels is more specific. ${ }^{28} \mathrm{In}$ the patients included in this study, hematuria was assessed in relation to urinary sediment and, although specificity was not studied, the authors believe that the concomitant presence of other criteria (hemolysis and thrombocytopenia) in a child (usually younger than 5 years) with a history of bloody diarrhea together with the local epidemiological context should lead to strongly suspect STEC-HUS. The impossibility of collecting urine due to anuria did not affect the diagnostic capability because all patients with anuria had high creatinine levels and thus met the renal criterion.

Lastly, the extended definition showed an excellent sensitivity because it does not include the presence of anemia or high creatinine levels as requirements; ${ }^{12}$ only 9 patients were not covered by this definition (and, therefore, by none of the definitions) due to the absence of thrombocytopenia or the impossibility of documenting a sharp drop in platelet count at the time of consultation. Extending this criterion by 
including a sharp drop in platelet count allowed to adequately classify 3 additional patients with normal counts, but in whom such decrease was confirmed. The 9 patients who could not be identified with the more flexible definition maintained normal platelet counts during the entire hospitalization and, although a decrease $>50 \%$ was documented in 1 of them, it was not considered sudden because it occurred after 3 days. The absence of thrombocytopenia is uncommon $(6-11 \%)^{12,29,30}$ in children with STECHUS; this is because, sometimes, the drop in the platelet count is transient and, therefore, goes undetected..$^{31}$ In addition, the absence of this criterion may have little clinical impact because it is usually observed in patients with a mild presentation. ${ }^{32,33}$ Some authors also propose an increase in immature platelet fraction $(>3 \%)$ as a marker of platelet consumption; ${ }^{12}$ this parameter was not studied in the patients included in this series. Last but not least, from an epidemiological perspective, it is also important to have a highly sensitive definition that will allow to implement timely isolation measures aimed at limiting bacterial dissemination. ${ }^{7}$

Although the number of patients analyzed in this study is large, there are some limitations. First of all, only patients with confirmed HUS diagnosis were included, so specificity was not assessed; however, due to the severity of this disease, knowing the sensitivity of the different definitions may be important to reduce to a minimum the number of patients that are not detected in a timely manner, especially in a country with such high incidence, as is the case of Argentina. A study conducted in Italy demonstrated that, at the time of admission, $25 \%$ of patients did not have anemia, $14 \%$ had normal creatinine levels, and $11 \%$ did not have thrombocytopenia; notably, no patient received a different diagnosis in the subsequent days. ${ }^{12}$ Another potential limitation of this study is that, during the long studied period, there were variations in the number of patients identified based on the different definitions, with the resulting alteration in their sensitivity (e.g., in recent years, there was a greater level of recognition of the presentation without anemia). ${ }^{21,34}$ However, this assumption was ruled out because no differences were observed when the sample was divided into 2 periods of similar length.

\section{CONCLUSION}

The different STEC-HUS definitions showed significant differences in diagnostic sensitivity. The extended definition reached a sensitivity above $95 \%$, so its generalized use may help to reduce diagnostic delays

\section{REFERENCES}

1. Khalid M, Andreoli S. Extrarenal manifestations of the hemolytic uremic syndrome associated with Shiga toxinproducing Escherichia coli (STEC HUS). Pediatr Nephrol. 2019; 34(12):2495-507.

2. Rivas M, Miliwebsky E, Chinen I, Deza N, Leotta GA. Epidemiología del síndrome urémico hemolítico en Argentina. Diagnóstico del agente etiológico, reservorios y vías de transmisión. Medicina (B Aires). 2006; 66(Suppl 3):27-32.

3. Alconcher LF, Coccia PA, Suarez ADC, Monteverde M, et al. Hyponatremia: a new predictor of mortality in patients with Shiga toxin-producing Escherichia coli hemolytic uremic syndrome. Pediatr Nephrol. 2018; 33(10):1791-8.

4. Grisaru S. Management of hemolytic-uremic syndrome in children. Int J Nephrol Renovasc Dis. 2014; 7:231-9.

5. Caletti MG, Petetta D, Jaitt M, Casaliba S, Gimenez A. Evaluación de costos directos e indirectos del tratamiento del síndrome urémico hemolítico en sus distintas etapas evolutivas. Medicina (B Aires). 2006; 66 (Supl. 3):22-6.

6. Argentina. Ministerio de Salud. Boletín Integrado de Vigilancia. 2014;SE30(222). [Accessed in: September 2020]. Available at: http:/ / www.msal.gob.ar/images/stories / boletines / Boletin $\% 20$ Integrado $\% 20$ De $\% 20$ Vigilancia $\% 20$ N222-SE30.pdf

7. Freedman SB, Eltorki M, Chui L, Xie J, et al. Province-Wide Review of Pediatric Shiga Toxin-Producing Escherichia coli Case Management. J Pediatr. 2017; 180:184-90.e1.

8. Argentina. Ministerio de Salud. Boletín Integrado de Vigilancia. Edición ampliada. 2020;SE2(481). [Accessed in: September 2020]. Available at: https://www.argentina. gob.ar/sites/default/files/biv_481_edicion_ampliada.pdf

9. Adragna M, Balestracci A. Microangiopatía trombótica en pediatría. In: Ferraris JR, Briones Orfila L (eds). Nefrología Pediátrica. $3^{\text {ra }}$ ed. Buenos Aires: Sociedad Argentina de Pediatría; 2017.p.171-80.

10. Ake JA, Jelacic S, Ciol MA, Watkins S, et al. Relative nephroprotection during Escherichia coli O157:H7 infections: association with intravenous volume expansion. Pediatrics. 2005; 115(6):e673-80.

11. Bielaszewska M, Köck R, Friedrich AW, von Eiff C, et al. Shiga toxin-mediated hemolytic uremic syndrome: time to change the diagnostic paradigm? PLoS One. 2007; 2(10):e1024.

12. Ardissino G, Possenti I, Tel F, Testa S, Paglialonga F. Time to change the definition of hemolytic uremic syndrome. Eur J Intern Med. 2014; 25(2):e29.

13. Davis TK, McKee R, Schnadower D, Tarr PI. Treatment of Shiga toxin-producing Escherichia coli infections. Infect Dis Clin North Am. 2013; 27(3):577-97.

14. Díaz Moreno A, Gálvez H. Valores normales de laboratorio. In: Ferraris JR, Briones Orfila L (eds). Nefrología Pediátrica. $3^{\text {ra }}$ ed. Buenos Aires: Sociedad Argentina de Pediatría; 2017.p.599-608.

15. Meyers KE. Evaluation of hematuria in children. Urol Clin North Am. 2004; 31(3):559-73.

16. Bergstein J. A practical approach to proteinuria. Pediatr Nephrol. 1999; 13(8):697-700.

17. Hawass NE. Comparing the sensitivities and specificities of two diagnostic procedures performed on the same group of patients. Br J Radiol. 1997; 70(832):360-6. 
18. Balestracci A, Meni Battaglia L, Toledo I, Martin SM, Alvarado C. Prodromal Phase of Hemolytic Uremic Syndrome Related to Shiga Toxin-Producing Escherichia coli: The Wasted Time. Pediatr Emerg Care. 2019 [published online ahead of print, July $\left.8^{\text {th }}, 2019\right]$.

19. McKee RS, Schnadower D, Tarr PI, Xie J, et al. Predicting Hemolytic Uremic Syndrome and Renal Replacement Therapy in Shiga Toxin-producing Escherichia coli-infected Children. Clin Infect Dis. 2020; 70(8):1643-51.

20. Balestracci A, Martin SM, ToledoI, Alvarado C, Wainsztein RE. Dehydration at admission increased the need for dialysis in hemolytic uremic syndrome children. Pediatr Nephrol. 2012; 27(8):1407-10.

21. Ardissino G, Daccò V, Testa S, Felice Civitillo C, et al. Hemoconcentration: a major risk factor for neurological involvement inhemolyticuremic syndrome. Pediatr Nephrol. 2015; 30(2):345-52.

22. Mody RK, Gu W, Griffin PM, Jones T, et al. Postdiarrheal hemolytic uremic syndrome in United States children: clinical spectrum and predictors of in-hospital death. $J$ Pediatr. 2015; 166(4):1022-9.

23. Rahman RC, Cobeñas CJ, Drut R, Amoreo OR, et al. Hemorrhagic colitis in postdiarrheal hemolytic uremic syndrome: retrospective analysis of 54 children. Pediatr Nephrol. 2012; 27(2):229-33.

24. Ardissino G, Tel F, Possenti I, Testa S, et al. Early Volume Expansion and Outcomes of Hemolytic Uremic Syndrome. Pediatrics. 2016; 137(1):e20152153.

25. Bonany P, Bilkis MD, Iglesias G, Braun A, et al. Fluid restriction versus volume expansion in children with diarrhea-associated HUS: a retrospective observational study. Pediatr Nephrol. 20201; 36(1):103-9.
26. Grisaru S, Midgley JP, Hamiwka LA, Wade AW, Samuel SM. Diarrhea-associated hemolytic uremic syndrome in southern Alberta: A long-term single-centre experience. Paediatr Child Health. 2011; 16(6):337-40.

27. Serebruany VL, Christenson MJ, Pescetti J, McLean RH. Hypoproteinemia in the hemolytic-uremic syndrome of childhood. Pediatr Nephrol. 1993; 7(1):72-3.

28. Tarr GAM, Oltean HN, Phipps AI, Rabinowitz P, Tarr PI. Case definitions of hemolytic uremic syndrome following Escherichia coli O157:H7 infection vary in validity. Int J Med Microbiol. 2018; 308(8):1121-7.

29. Siegler RL, Pavia AT, Christofferson RD, Milligan MK. A 20-year population-based study of postdiarrheal hemolytic uremic syndrome in Utah. Pediatrics. 1994; 94(1):35-40.

30. Schifferli A, von Vigier RO, Fontana M, Spartà G, et al. Hemolytic-uremic syndrome in Switzerland: a nationwide surveillance 1997-2003. Eur J Pediatr. 2010; 169(5):591-8.

31. JohnsonS, Mark Taylor CM. Hemolytic Uremic Syndrome. In: Avner ED, Harmon WH, Niaudet P, Yoshikawa N (eds). Pediatric Nephrology. $6^{\text {th }}$ ed. Berlin Heidelberg: Springer Verlag; 2009.p.1155-80.

32. Tarr PI. Shiga toxin-associated hemolytic uremic syndrome and thrombotic thrombocytopenic purpura: distinct mechanisms of pathogenesis. Kidney Int Suppl. 2009; (112):S29-32.

33. Balestracci A, Toledo I, Meni Battaglia L, de Lillo L, et al. Postdiarrhoeal haemolytic uraemic syndrome without thrombocytopenia. Nefrologia. 2017; 37(5):508-14.

34. Balestracci A, Martin SM, Toledo I. Hemoconcentration in hemolytic uremic syndrome: time to review the standard case definition? Pediatr Nephrol. 2015; 30(2):361. 